\section{Phytotoxic Effects of Acetic Acid and d-limonene on Four Aquatic Plants}

\author{
Lyn A. Gettys ${ }^{1}$, Kyle L. Thayer ${ }^{1}$, and Joseph W. Sigmon ${ }^{1}$
}

\begin{abstract}
AdDitional Index words. Azolla pinnata, cattail, Eleocharis cellulosa, feathered mosquitofern, invasive species, natural herbicides, organic herbicides, Salvinia minima, spikerush, Typha latifolia, vinegar
\end{abstract}

SumMARY. Herbicides that are labeled for aquatic use are often the foundation of aquatic vegetation management programs in the United States because many of these products, which are registered by the U.S. Environmental Protection Agency, are effective, selective, and relatively inexpensive. Resource managers are interested in reducing the use of synthetic herbicides and are considering alternative methods for aquatic weed control. We evaluated the effects of acetic acid and d-limonene on growth of the invasive small floating species feathered mosquitofern (Azolla pinnata) and common salvinia (Salvinia minima), as well as on the native emergent wetland plants cattail (Typha latifolia) and gulf coast spikerush (Eleocharis cellulosa). Acetic acid and d-limonene (alone and in combination) were applied once as foliar treatments to healthy plants, which were grown for 8 weeks after treatment to allow for development of phytotoxicity symptoms. All experiments also included diquat dibromide at three concentrations as "industry-standard" treatments for comparison. A $0.22 \%$ concentration of diquat dibromide eliminated all vegetation of all species. Most single-product treatments provided good control of invasive feathered mosquitofern with acceptable levels of damage to native gulf coast spikerush, but only $15 \%$ and $20 \%$ d-limonene treatments were effective on invasive common salvinia and selective for native cattail. Some combinations of acetic acid and d-limonene provided acceptable control of both floating weeds and selectivity for gulf coast spikerush, but all mixes caused unacceptable levels of damage to cattail. Treating these small floating weeds with acetic acid and d-limonene instead of diquat dibromide would increase material costs by 15 - to 27 -fold. Although these natural products may be useful in some areas where synthetic herbicides are discouraged, they are unlikely to be affordable options for most resource managers.

$\mathrm{R}$ esource managers are responsible for ensuring that aquatic yegetation does not interfere

Received for publication 4 Nov. 2021. Accepted for publication 29 Nov. 2021.

Published online 1 February 2022

${ }^{1}$ University of Florida Institute of Food and Agricul tural Sciences Fort Lauderdale Research and Education Center, 3205 College Avenue, Davie, FL 33314

This paper is based on a presentation given at the 2021 Florida State Horticultural Society's annual meeting in Sept. 2021. This research was supported by the Florida Agricultural Experiment Station and by the U.S. Department of Agriculture National Institute of Food and Agriculture (HATCH project FLA-FTL-005682). Funding was provided by the Florida Fish and Wildlife Conservation Commission. Mention of a trademark, proprietary product or vendor does not constitute a guarantee or warranty of the product and does not imply its approval to the exclusion of other products or vendors that also may be suitable.

We thank Angie Diez and Carrie Thor for their invaluable contributions to this project.

L.A.G. is the corresponding author. E-mail: lgettys@ufl.edu.

This is an open access article distributed under the CC BY-NC-ND license (https://creativecommons. org/licenses/by-nc-nd/4.0/).

https://doi.org/10.21273/HORTTECH04986-21 with navigation, flood control efforts, and other uses of state waters. Aquatic weeds are most often managed with herbicides that have been approved by the U.S. Environmental Protection Agency (USEPA) for use in aquatic systems. In Florida, statewide oversight and coordination of aquatic weed management programs are provided by the Florida Fish and Wildlife Conservation Commission (FWC), which oversees tens of millions of dollars in federal and state funds to control aquatic plants in Florida's public water bodies (Florida Fish and Wildlife Conservation Commission, 2018, 2019). The bulk of funding is used to manage the submersed weed hydrilla (Hydrilla verticillata), with $\approx 25 \%$ of those monies spent for floating plant control, which primarily comprise waterhyacinth (Eichhornia crassipes) and waterlettuce (Pistia stratiotes).

Floating plants can block the air-water interface, thus reducing the penetration of oxygen and light into the water column, and interfere with flood control operations by creating mats that obstruct canals and clog water movement structures (Gettys, 2019). Although waterhyacinth and waterlettuce are the most problematic floating plants in Florida, there are a number of other floating species that are intensively managed in the state, including the diminutive but invasive feathered mosquitofern (Azolla pinnata) and common salvinia (Salvinia minima). Feathered mosquitofern, a federal noxious weed, is an Australian native that has been used primarily in Asia for improving rice (Oryza sativa) production because of its symbiotic relationship with a nitrogen-fixing bacterium (Bodle, 2008; Madeira et al., 2013). Common salvinia, a South American species that was first reported in Florida in the 1920s, is less aggressive than feathered mosquitofern, but it has the potential for explosive growth and is frequently targeted for management (Jacono et al., 2001; Tipping et al., 2012). Both species are attractive ferns that are thought to have arrived in Florida's waters after escaping cultivation in fish tanks and water gardens.

Herbicides are only labeled for aquatic use by the USEPA if they "will not generally cause unreasonable

\begin{tabular}{llll}
\hline $\begin{array}{l}\text { Units } \\
\text { To convert U.S. to SI, } \\
\text { multiply by }\end{array}$ & U.S. unit & SI unit & $\begin{array}{l}\text { To convert SI to U.S., } \\
\text { multiply by }\end{array}$ \\
\hline 0.4047 & acre $(\mathrm{s})$ & $\mathrm{ha}$ & 2.4711 \\
29.5735 & $\mathrm{fl} \mathrm{oz}$ & $\mathrm{mL}$ & 0.0338 \\
3.7854 & $\mathrm{gal}$ & $\mathrm{L}$ & 0.2642 \\
9.3540 & gal/acre & $\mathrm{L} \cdot \mathrm{ha}^{-1}$ & 0.1069 \\
2.54 & inch $(\mathrm{es})$ & $\mathrm{cm}$ & 0.3937 \\
25.4 & inch $(\mathrm{es})$ & $\mathrm{mm}$ & 0.0394 \\
0.4536 & lb & $\mathrm{kg}$ & 2.2046 \\
1.1209 & $\mathrm{lb} / \mathrm{acre}$ & $\mathrm{kg} \cdot \mathrm{ha}^{-1}$ & 0.8922 \\
28.3495 & $\mathrm{oz}$ & $\mathrm{g}$ & 0.0353 \\
70.0532 & $\mathrm{oz} / \mathrm{acre}$ & $\mathrm{g} \cdot \mathrm{ha}^{-1}$ & 0.0143 \\
$\left({ }^{\circ} \mathrm{F}-32\right) \div 1.8$ & ${ }^{\circ} \mathrm{F}$ & ${ }^{\circ} \mathrm{C}$ & $\left({ }^{\circ} \mathrm{C} \times 1.8\right)+32$
\end{tabular}


adverse effects on the environment... taking into account the economic, social, and environmental costs and benefits of the use of any pesticide" (U.S. Environmental Protection Agency, 1996). However, public concerns regarding aquatic herbicide use have driven efforts to find new ways for managers to practice aquatic weed control while reducing reliance on synthetic herbicides. These efforts include exploring the effects of "natural" herbicides that are sometimes used in home gardens and organic farming. Gettys et al. (2021) reviewed the literature regarding the use of these types of products for terrestrial weed control and evaluated the effects and selectivity of acetic acid, $\mathrm{d}$-limonene, and combinations of the two on waterhyacinth, waterlettuce, pickerelweed (Pontederia cordata), and broadleaf sagittaria (Sagittaria latifolia). They reported that some combinations of acetic acid and d-limonene had acceptable effects on the invasive species and selectivity on pickerelweed and broadleaf sagittaria, but that product and labor costs would be significantly higher than those incurred with synthetic herbicides (Gettys et al., 2021). Additionally, acetic acid and d-limonene are not labeled for use as aquatic herbicides at the concentrations evaluated; therefore, environmental fate, ecological toxicity, and other information needed for USEPA approval may be unavailable (Stubbs and Layne, 2020).

Based on previous work reported by Gettys et al. (2021), the primary goals of these experiments were to evaluate efficacy and selectivity of acetic acid and d-limonene (alone and in combination with each other) on two floating invasive target species and two emergent desirable nontarget species, and to compare the costs of using these products vs. the synthetic USEPA-approved aquatic herbicide diquat dibromide.

\section{Materials and methods}

EFFicacy studies. Target (weed) species were feathered mosquitofern and common salvinia, and nontarget (desirable) species were gulf coast spikerush (Eleocharis cellulosa) and cattail (Typha latifolia). Plants were treated in pairs of one invasive floating species and one native emergent species. "Run l" focused on feathered mosquitofern and gulf coast spikerush, whereas "Run 2" focused on common salvinia and cattail.

Target species were field-collected or pulled from cultures maintained at the University of Florida Fort Lauderdale Research and Education Center (FLREC) in Davie, FL, and moved to 18-gal plastic tubs filled with well water. All tubs were amended with $10 \mathrm{~g}$ of crushed $15 \mathrm{~N}-3.9 \mathrm{P}-10 \mathrm{~K}$ controlled-release fertilizer formulated for 6-month release in Florida (Osmocote Plus; ICL Specialty Fertilizers, Dublin, $\mathrm{OH}), 1.2 \mathrm{~g}$ of $7 \mathrm{~N}-0 \mathrm{P}-0 \mathrm{~K}$ iron chelate micronutrient (Sprint 330; BASF Corp., Research Triangle Park, NC), and $3.4 \mathrm{~g}$ of $24 \mathrm{~N}-3.5 \mathrm{P}-13.3 \mathrm{~K}$ watersoluble fertilizer (Miracle-Gro Water Soluble All Purpose Plant Food; Scotts Miracle-Gro Products, Marysville, $\mathrm{OH})$. Each tub was initially "seeded" with enough plants of a target species to cover $\approx 25 \%$ of the water's surface; then, plants were grown for 4 to 6 weeks to allow the development of $>80 \%$ surface coverage.

Nontarget species were purchased from an aquatic nursery (Aquatic Plants of Florida, Myakka City, FL) and transported to a greenhouse at FLREC, where individual plants were transplanted to 2 -L plastic pots without holes that were filled with sand [grain diameter 0.25-0.5 mm (MultiPurpose Sand; Sakrete, Charlotte, $\mathrm{NC})$ ] amended with $4 \mathrm{~g}$ of the same controlled-release fertilizer used in the tubs. Plants were grown on greenhouse benches and irrigated twice per day (10:00 $\mathrm{AM}$ and 4:00 $\mathrm{PM}$ ) with the equivalent of 0.5 inches of water per irrigation before being used in experiments. New shoots were cut back during this culture period to ensure that each 2 -L pot contained a single nontarget plant. When target plant coverage reached $>80 \%$ of the surface of the water, one potted nontarget plant was introduced to each tub (water depth $\approx 20 \mathrm{~cm}$ above the surface of the pots) and all plants were then subjected to treatment.

Treatments were applied as single spot "spray to wet" foliar applications (50 $\mathrm{mL}$ solution per mesocosm) to above-water foliage, and all treatments included $1 \% \mathrm{v} / \mathrm{v}$ of a nonionic surfactant (Induce; Helena Agri-Enterprises, Collierville, TN) to aid in penetration and emulsification. Nine single-product treatments $(5 \%, 7.5 \%, 10 \%, 15 \%$, and $20 \%$ acetic acid; $10 \%, 15 \%, 20 \%$, and 30\% d-limonene), 20 combination treatments (all combinations of single acetic acid and d-limonene treatments), three synthetic standard practice treatments $(0.22 \%, 0.45 \%$, and $0.89 \%$ diquat dibromide), and an untreated control were evaluated, with four replicates of each treatment. Base materials were 30\% acetic acid (Green Gobbler 30\% Vinegar Home and Garden; EcoClean Solutions, Copiague, NY), 100\% d-limonene (100\% Pure Technical Grade D-Limonene; EcoClean Solutions), and $37.3 \%$ diquat dibromide (Tribune Herbicide; Syngenta Crop Protection, Greensboro, NC). Treatments were applied to Run 1 and Run 2 plants on 10 Sept. 2020 and 28 Jan. 2021 , respectively.

Plants were monitored weekly for 8 weeks after treatment and then assigned a numerical value of 0 through 10 to describe the visual quality $(0=$ dead; 5 = fair quality, acceptable, somewhat desirable form and color, little to no chlorosis or necrosis; $10=$ excellent quality, perfect condition, healthy and robust, excellent color and form). We recorded visual quality, which has been used to describe the plant response to differing culture conditions (Gettys and Moore, 2018, 2019; Gettys et al., 2021), herbicides ( Gettys and Haller, 2009, 2010, 2012; Smith et al., 2014), salt stress (Tootoonchi et al., 2020), and other experimental factors, although some researchers (Cutelle et al., 2013; Koschnick et al., 2005; Mudge et al., 2007) have reported visual injury or damage resulting from herbicide treatments. After visual scoring, a destructive harvest was conducted to collect all live biomass of floating species and all live aboveground shoots of emergent species; harvested materials were placed in paper bags and moved to a forced-air oven maintained at $65^{\circ} \mathrm{C}$ for 2 weeks before being weighed. Visual evaluations and destructive harvests occurred 5-7 Nov. 2020 (Run 1) and 25-27 Mar. 2021 (Run 2).

While conducting destructive harvests, we realized that visual quality alone might not be a good indicator of treatment efficacy on feathered mosquitofern and common salvinia. For example, some mesocosms had very few live plants remaining, but the plants that were still alive were in excellent condition. We added a record of percent coverage of these small floating species in each mesocosm to describe 
this observation. Then, we developed an additional metric - "VC"- to better describe treatment effects on both target species, where $\mathrm{VC}$ is visual quality $\times$ percent coverage. Visual quality and VC data were arcsin-transformed before analysis to normalize distribution. Data within each species were evaluated using a generalized linear model (SAS version 9.4; SAS Institute, Cary, NC) to determine whether treatment means differed from those of untreated plants at $P=0.05$. Treatment means of visual values, $\mathrm{VC}$, and dried biomass were then compared with those of untreated controls. Haller and Gettys (2013) reported that an ideal herbicide treatment should cause a $>90 \%$ reduction in these parameters in target weeds and a $<50 \%$ reduction in nontarget native plants. Therefore, we used these values as benchmarks for efficacy on the floating weeds feathered mosquitofern and common salvinia and selectivity on the emergent native plants gulf coast spikerush and cattail.
Cost comparisons. Most diquat dibromide used by FWC in fiscal year 2018-19 was applied as Tribune (Syngenta Crop Protection) (Clark and Dew, 2019). FWC's negotiated contract price was $\$ 35.50 / \mathrm{gal}$, which was used for cost comparisons. As mentioned previously, the base "natural" products used in these experiments were $30 \%$ acetic acid and technicalgrade d-limonene. Bulk purchase prices for these were $\$ 8.00 / \mathrm{gal}$ (30\% acetic acid, 275-gal tote) and $\$ 31.82 / \mathrm{gal}$ (technical grade d-limonene, $4 \times 55$ gal drums) (Factory Direct Chemicals, 2019a, 2019b). Cost comparisons used a purchase price of $\$ 8.00 / \mathrm{gal}$ for $30 \%$ acetic acid and \$31.82/gal for technical grade d-limonene.

\section{Results and discussion}

SINGLE PRODUCTs. Diquat dibromide at $0.22 \%, 0.45 \%$, and $0.89 \%$ completely eliminated all live biomass of both floating weeds and both nontarget native plants. Thus, as with
Gettys et al. (2021), diquat dibromide treatments were removed from datasets before further statistical analyses were conducted because most natural treatments were much less effective than diquat dibromide, and comparisons between natural treatments and untreated controls would be more informative.

Most single-product treatments provided good control of feathered mosquitofern in respect to biomass, and the only single-product natural herbicide treatments that failed to reduce biomass by at least $90 \%$ were $5 \%$ and $7.5 \%$ acetic acid $[P<0.01$ (Fig. 1A)]. Only three single-product natural treatments (d-limonene at $15 \%$, $20 \%$, or $30 \%$ ) reduced visual quality of feathered mosquitofern by $90 \%[P<$ 0.01 (Fig. 2A)]. As with biomass, the only single-product natural herbicide treatments that failed to reduce VC by at least $90 \%$ were $5 \%$ and $7.5 \%$ acetic acid $[P<0.01$ (Fig. 3A)]. Gulf coast spikerush was less affected by these
A

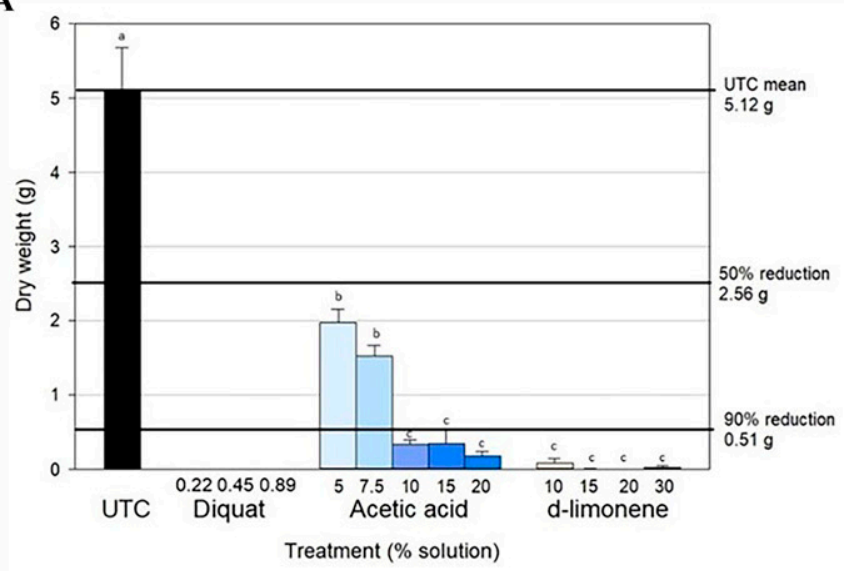

C

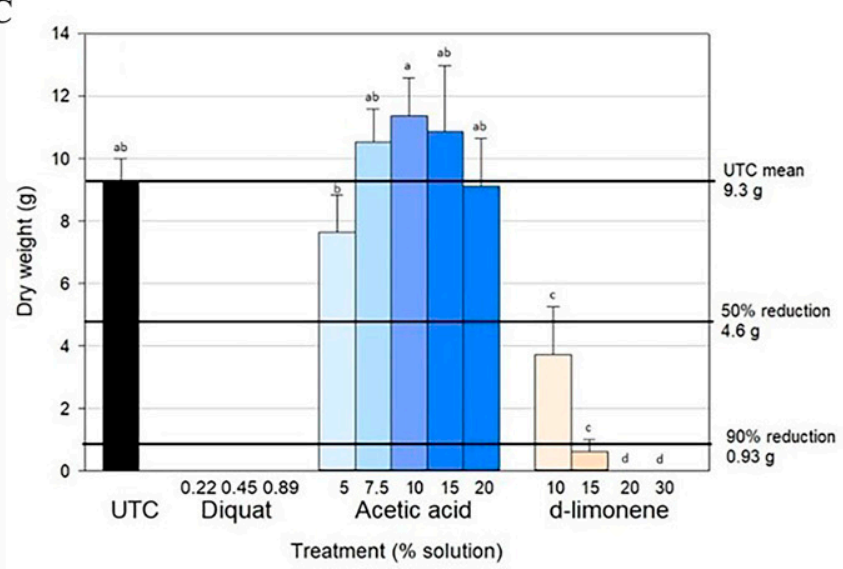

B

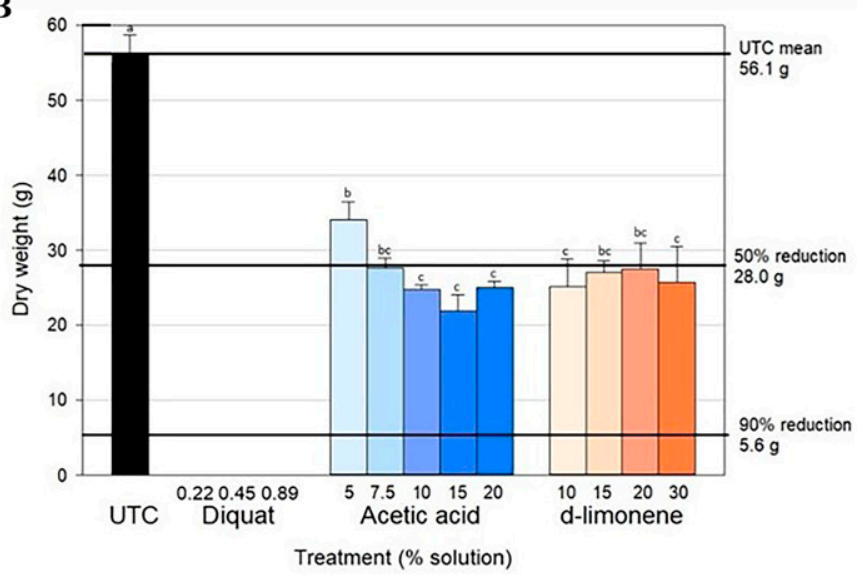

D

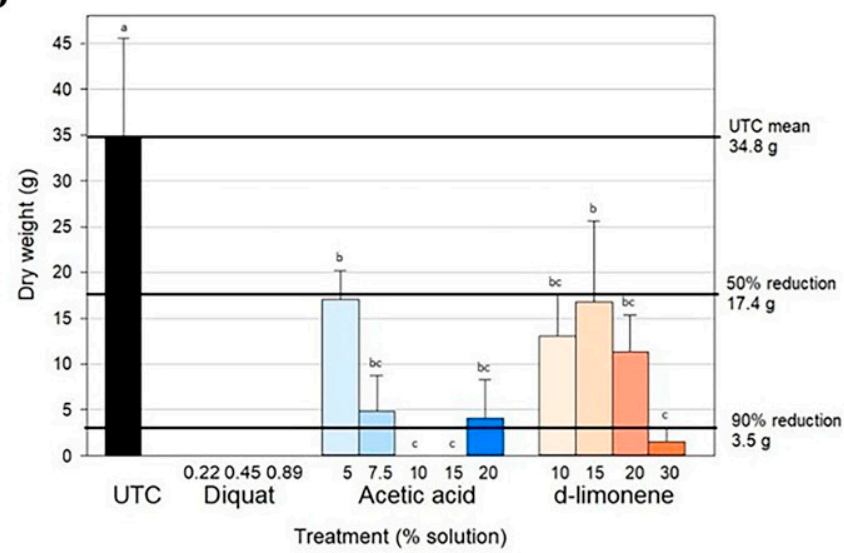

Fig. 1. Biomass of (A) feathered mosquitofern, (B) gulf coast spikerush, (C) common salvinia, and (D) cattail 8 weeks after singleproduct treatment. Bars are the mean of four replicates and error bars are $1 \mathrm{sD}$ from the mean. Treatments coded with the same letter are not different at $\boldsymbol{P}=\mathbf{0 . 0 5}$. The upper bold horizontal rule indicates the mean of untreated control (UTC) plants, whereas the central and lower bold horizontal rules indicate $50 \%$ and $90 \%$ reductions compared with UTC plants; $1 \mathrm{~g}=0.0353 \mathrm{oz}$. 
A

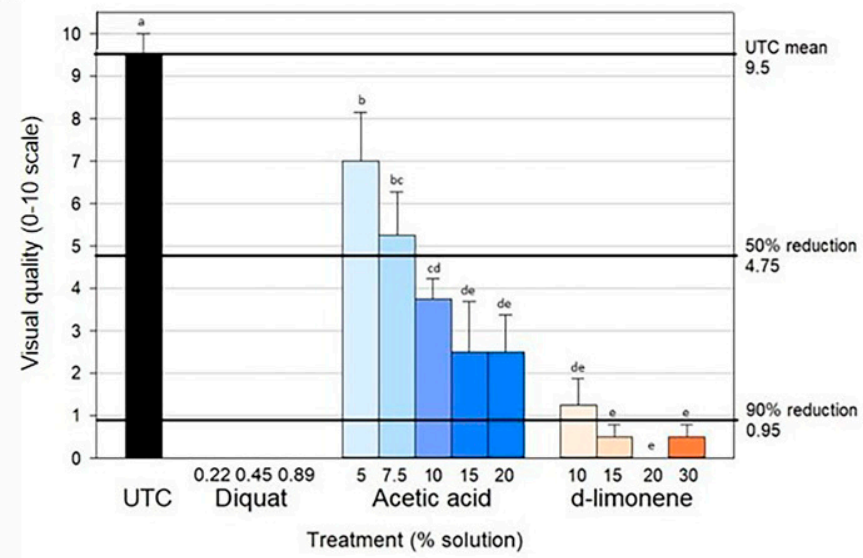

C

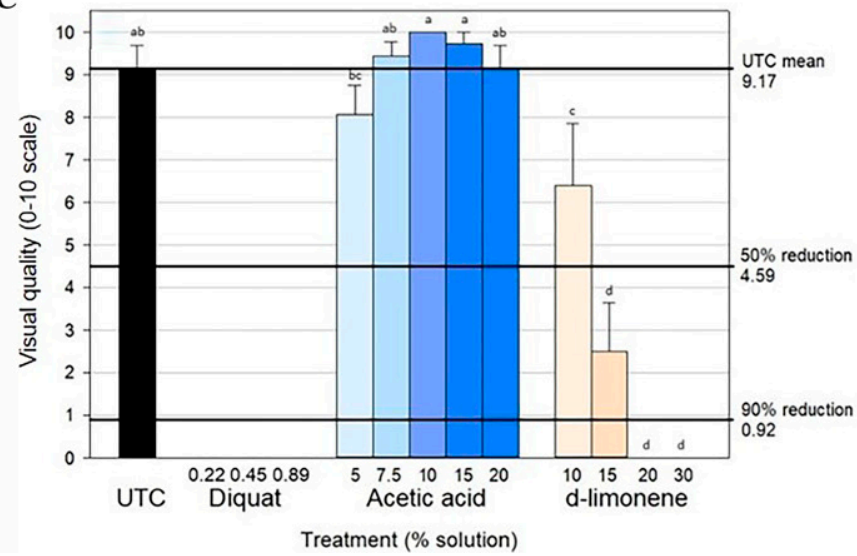

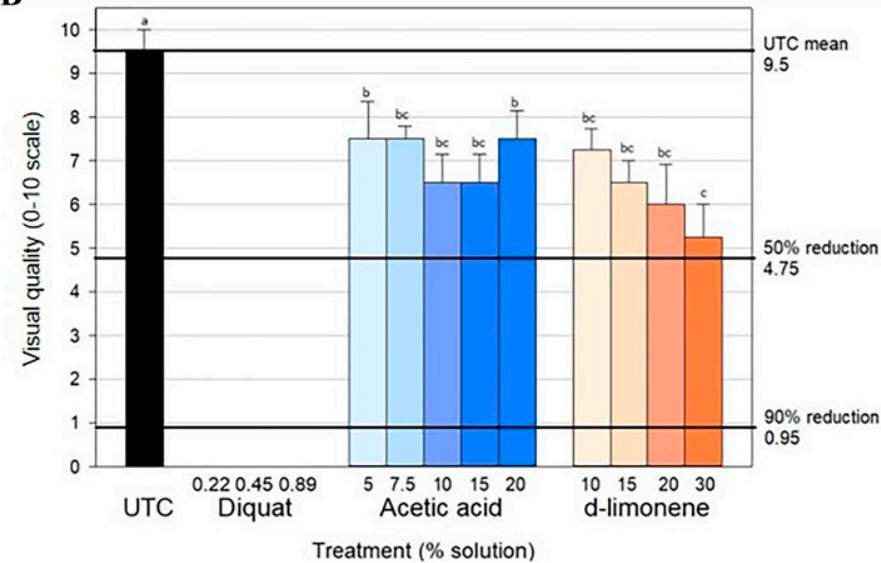

D

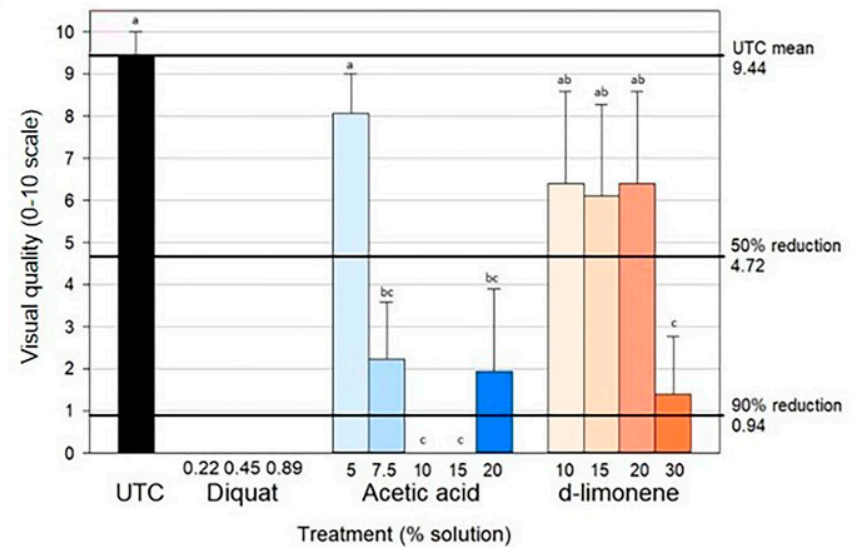

Fig. 2. Visual quality of (A) feathered mosquitofern, (B) gulf coast spikerush, (C) common salvinia, and (D) cattail 8 weeks after single-product treatment. A numerical scale of 0 through 10 is used to describe visual quality, where $0=$ dead; $5=$ fair quality, acceptable, somewhat desirable form and color, little to no chlorosis or necrosis; and $10=$ excellent quality, perfect condition, healthy and robust, excellent color and form. Bars are the mean of four replicates and error bars are 1 SD from the mean. Treatments coded with the same letter are not different at $P=0.05$. The upper bold horizontal rule indicates the mean of untreated control (UTC) plants, whereas the central and lower bold horizontal rules indicate $50 \%$ and $90 \%$ reductions compared with UTC plants.

treatments than feathered mosquitofern. Most single-product natural herbicide treatments reduced biomass by $\approx 50 \%[P<0.01$ (Fig. 1B)], whereas reductions in visual quality ranged from $\approx 20 \%$ to $45 \%$ [ $P<0.01$ (Fig. $2 B$ )]. This level of damage is acceptable for nontarget species, and it is likely that gulf coast spikerush would completely recover from these treatments if given more time.

In contrast to feathered mosquitofern, most single-product treatments failed to provide good control of common salvinia in respect to biomass $[P<0.01$ (Fig. 1C)], visual quality $[P<0.01$ (Fig. $2 \mathrm{C}$ ) $]$, and VC $[P<$ 0.01 (Fig. $3 \mathrm{~B}$ )], and the only singleproduct natural herbicide treatments that reduced these parameters by at least $90 \%$ were $20 \%$ and $30 \%$ d-limonene. Also, dry weight, visual quality, and VC of common salvinia treated with any concentration of acetic acid were equal to (or greater than) those of untreated plants. Cattail was much more sensitive to acetic acid and less sensitive to d-limonene than common salvinia, and all single-product treatments reduced cattail biomass by at least $50 \%$ compared with untreated plants $[P<$ 0.01 (Fig. 1D)]. Applications of $\geq 7.5 \%$ acetic acid reduced biomass by $>80 \%$, whereas only the highest d-limonene concentration $(30 \%)$ reduced biomass by at least $90 \%$ compared with that of untreated plants, although visual quality $[P<0.01$ (Fig. 2D)] was less affected by all treatments. If selective management of common salvinia with low levels of damage to nontarget cattail is desired, then applications of $15 \%$ or $20 \%$ d-limonene may be viable options.

ACETIC ACID AND D-LIMONENE MIXEs. All combinations of acetic acid and d-limonene had good efficacy on feathered mosquitofern. Biomass
$[P<0.01$ (Fig. 4A)], visual quality $[P<0.01$ (Fig. 5A) $]$, and VC $[P<$ 0.01 (Fig. 6A)] were reduced by $>90 \%$ compared with untreated controls. Most treatments reduced biomass of gulf coast spikerush by between $50 \%$ and $75 \%[P<0.01$ (Fig. 4B)], but only two combinations reduced visual quality by $>50 \%[P<0.01$ (Fig. $5 \mathrm{~B})]$. As with the single-product treatments, this level of damage is acceptable for nontarget species, and it is likely that gulf coast spikerush would completely recover from these treatments if given more time.

Virtually all combinations of acetic acid and d-limonene had good efficacy on common salvinia. With the exception of plants treated with 5\% acetic acid plus $10 \%$ d-limonene, biomass $[P<0.01$ (Fig. 4C) $]$ and VC $[P<0.01$ (Fig. 6B)] were reduced by $>85 \%$ compared with untreated common salvinia. Unfortunately, cattail 
A

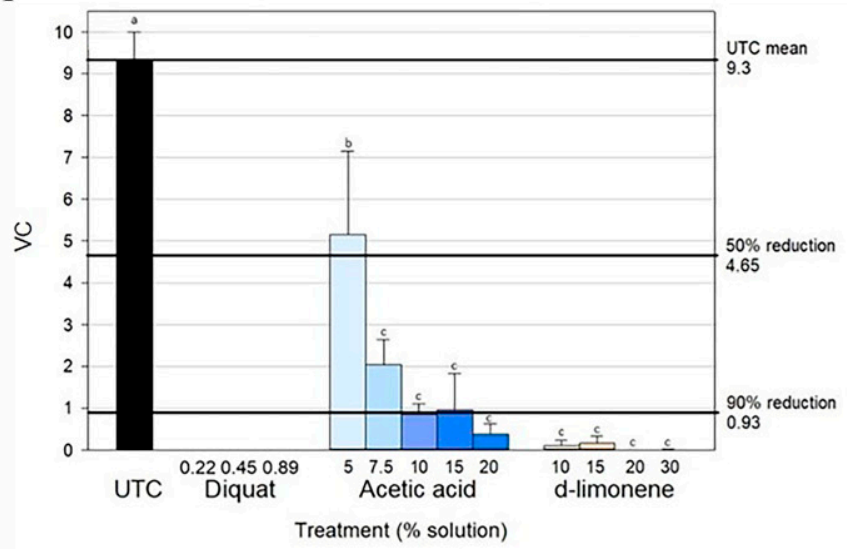

B

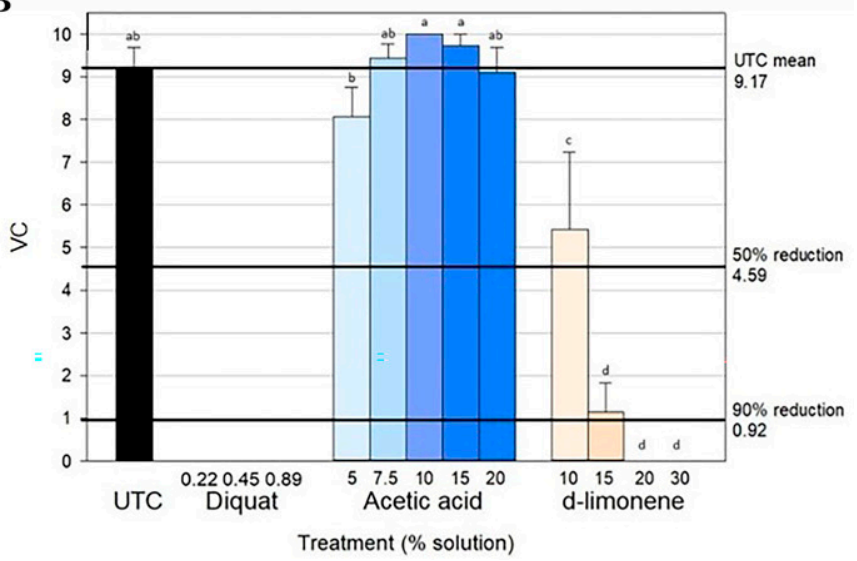

Fig. 3. VC (visual quality $\times$ percent coverage) of (A) feathered mosquitofern and (B) common salvinia 8 weeks after singleproduct treatment. Bars are the mean of four replicates and error bars are 1 sD from the mean. Treatments coded with the same letter are not different at $P=\mathbf{0 . 0 5}$. The upper bold horizontal rule indicates the mean of untreated control (UTC) plants, whereas the central and lower bold horizontal rules indicate $50 \%$ and $90 \%$ reductions compared with UTC plants.

biomass was affected by treatments in a similar manner $[P<0.01$ (Fig. 4D)], although visual quality was less affected
$[P<0.01$ (Fig. 5D)]. Therefore, these combinations of acetic acid and d-limonene should not be used for selective control of common salvinia because of the unacceptable levels of damage to cattail.
A

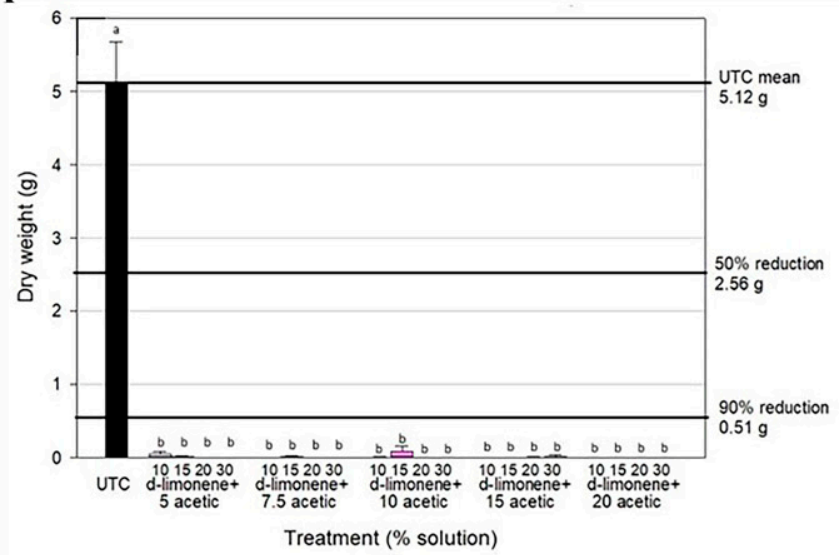

C

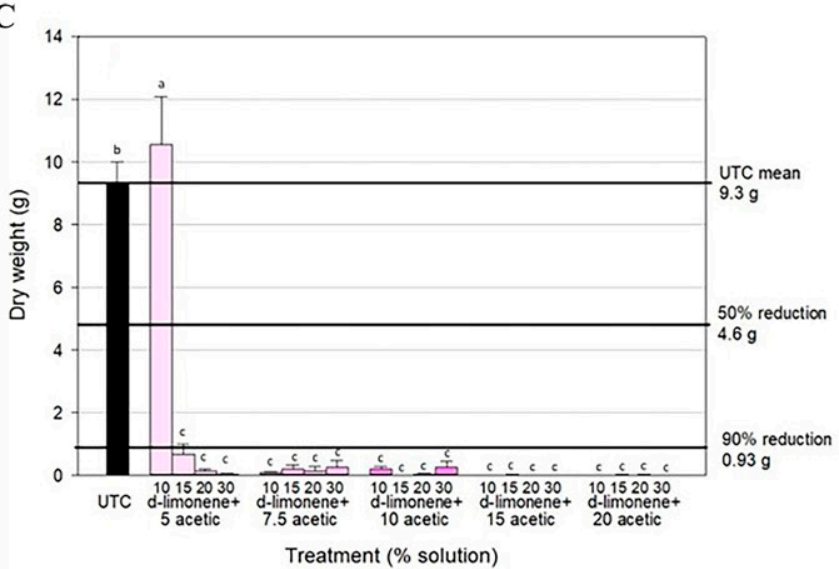

B

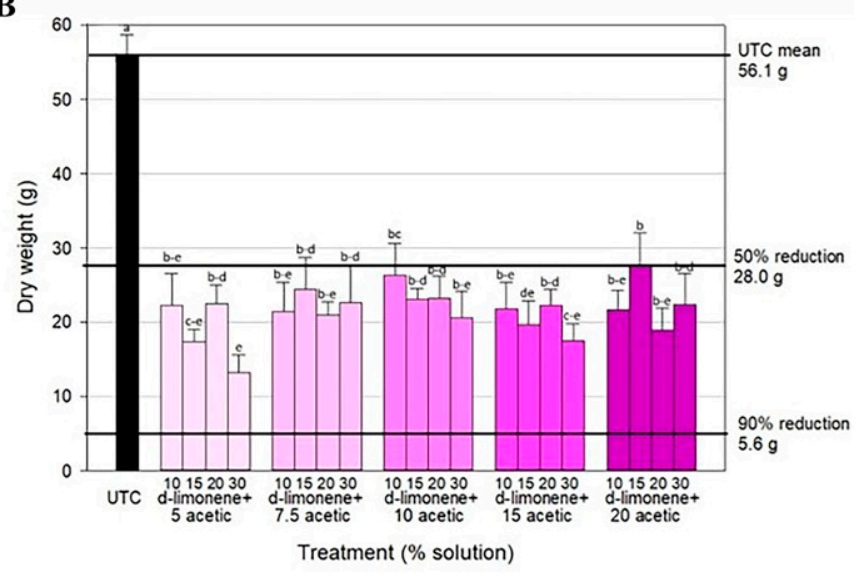

D

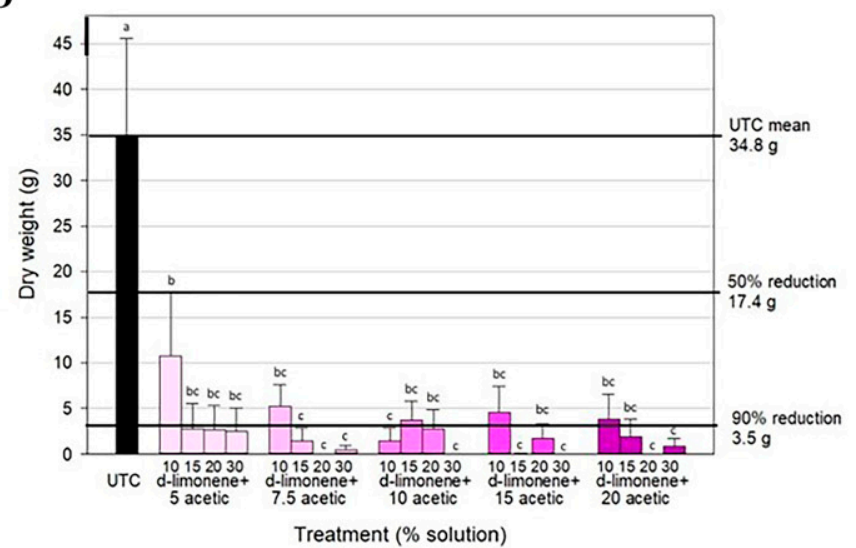

Fig. 4. Biomass of (A) feathered mosquitofern, (B) gulf coast spikerush, (C) common salvinia, and (D) cattail 8 weeks after treatment with combinations of acetic acid and $\mathrm{d}$-limonene. Bars are the mean of four replicates and error bars are $1 \mathrm{sD}$ from the mean. Treatments coded with the same letter are not different at $\boldsymbol{P}=\mathbf{0 . 0 5}$. The upper bold horizontal rule indicates the mean of untreated control (UTC) plants, whereas the central and lower bold horizontal rules indicate $50 \%$ and $90 \%$ reductions compared with UTC plants; $1 \mathrm{~g}=\mathbf{0 . 0 3 5 3} \mathrm{oz}$. 
$\mathbf{A}$

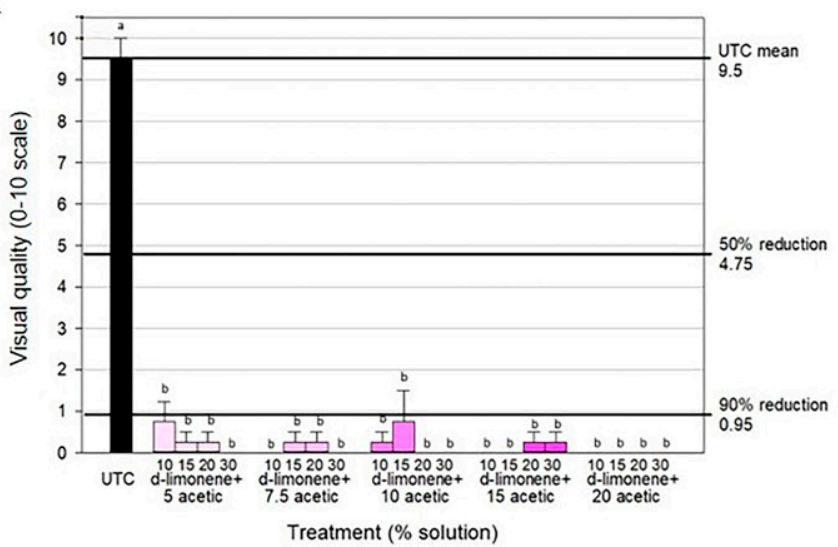

C

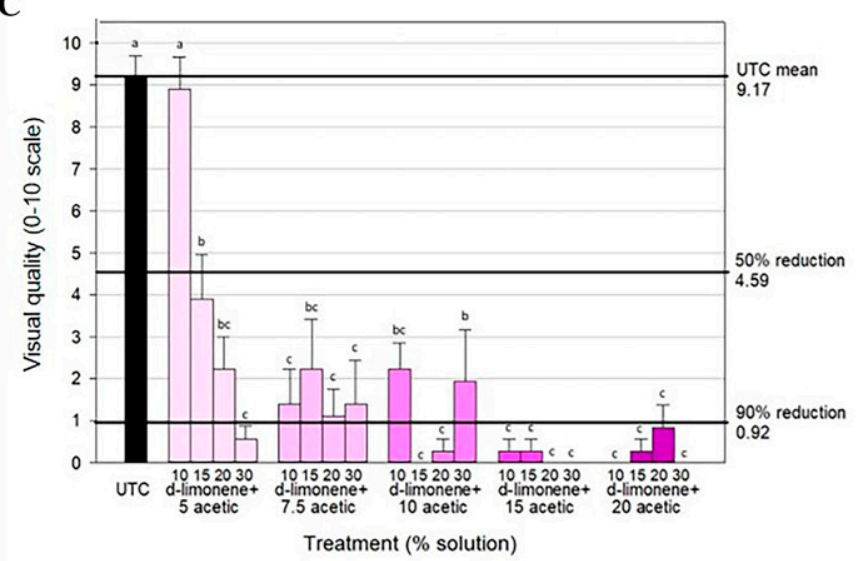

B

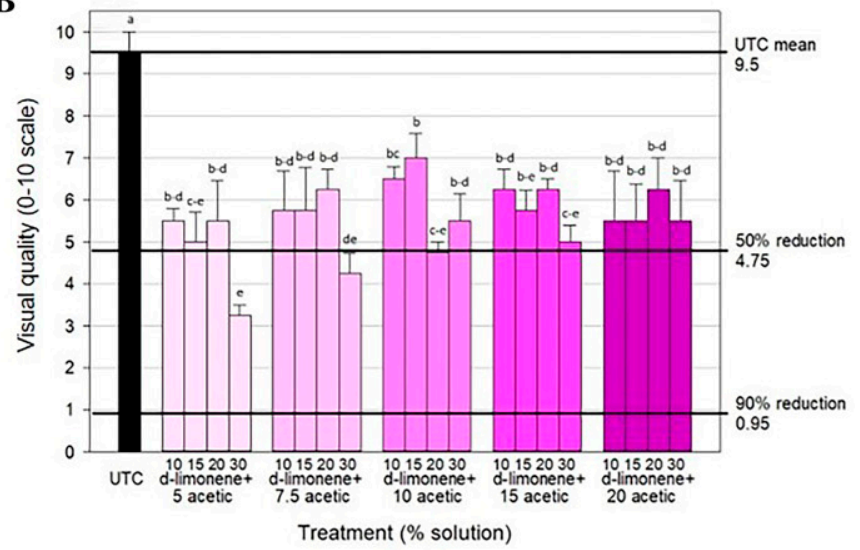

D

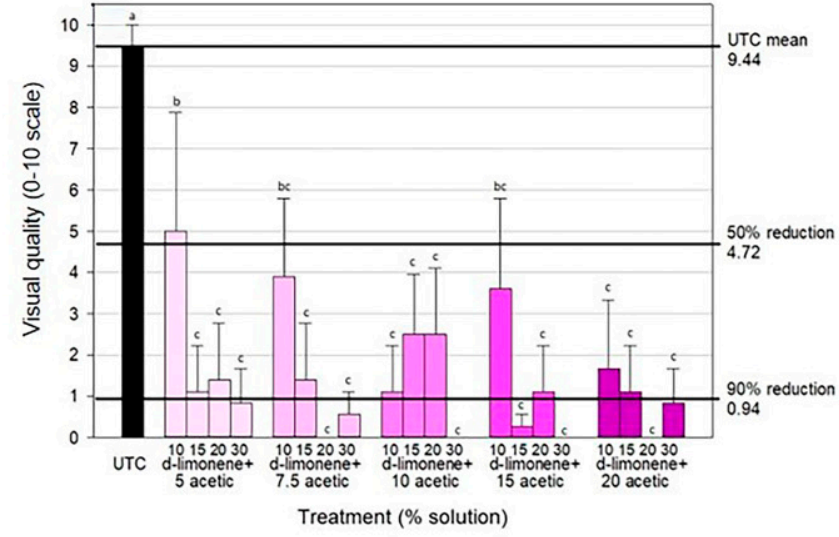

Fig. 5. Visual quality of (A) feathered mosquitofern, (B) gulf coast spikerush, (C) common salvinia, and (D) cattail 8 weeks after treatment with combinations of acetic acid and d-limonene. A numerical scale of 0 through 10 is used to describe visual quality, where $\mathbf{0}=$ dead; $\mathbf{5}$ = fair quality, acceptable, somewhat desirable form and color, little to no chlorosis or necrosis; and 10 = excellent quality, perfect condition, healthy and robust, excellent color and form. Bars are the mean of four replicates and error bars are 1 SD from the mean. Treatments coded with the same letter are not different at $P=0.05$. The upper bold horizontal rule indicates the mean of untreated control (UTC) plants, whereas the central and lower bold horizontal rules indicate $50 \%$ and $90 \%$ reductions compared with UTC plants.

These results suggest that treatments using acetic acid, d-limonene, or combinations of the two may be useful for managing populations of invasive feathered mosquitofern and common salvinia while allowing selectivity with reduced damage to the native plants gulf coast spikerush and cattail.
A

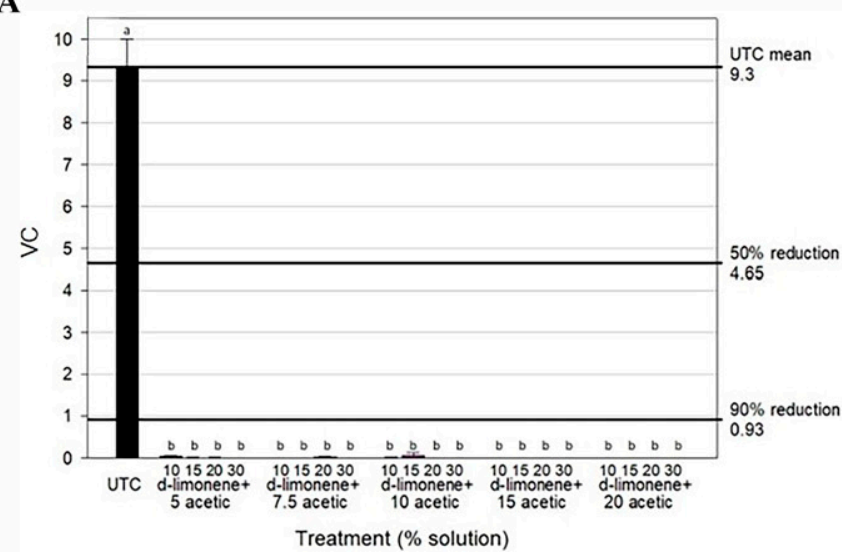

B

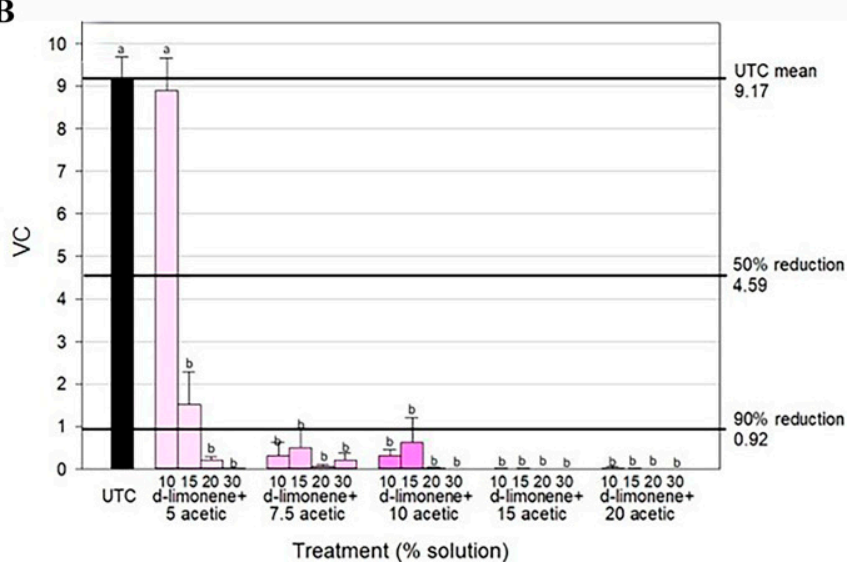

Fig. 6. VC (visual quality $\times$ percent coverage) of (A) feathered mosquitofern and (B) common salvinia 8 weeks after singleproduct treatment. Bars are the mean of four replicates and error bars are 1 sD from the mean. Treatments coded with the same letter are not different at $\boldsymbol{P}=\mathbf{0 . 0 5}$. The upper bold horizontal rule indicates the mean of untreated control (UTC) plants, whereas the central and lower bold horizontal rules indicate $50 \%$ and $\mathbf{9 0 \%}$ reductions compared with UTC plants. 


\section{COST ANALYSIS OF ACETIC ACID AND} D-LIMONENE MIXES FOR SMALL FLOATING WEED MANAGEMENT. The synthetic standard practice treatments in these experiments used diquat dibromide and simulated spot foliar field treatments. Although we evaluated three concentrations $(0.22 \%, 0.45 \%$, and $0.89 \%$ ) of diquat dibromide, the lowest concentration completely eliminated all plant material; therefore, calculations are based on spot treatments using a $0.22 \%$ solution. FWC's negotiated contract price for $37.3 \%$ diquat dibromide was $\$ 35.50 / \mathrm{gal}$; therefore, after dilution to a $0.22 \%$ concentration, the final cost of ready-to-use (RTU) mix is $\$ 0.1775 / \mathrm{gal}$. If all treatments are mixed to a concentration of $0.22 \%$ diquat dibromide and applied in a carrier volume equivalent to $100 \mathrm{gal} / \mathrm{acre}$ as indicated on the herbicide label (Syngenta Crop Protection, 2011), then the material cost per acre treated with the synthetic standard diquat dibromide is $\$ 17.75$. As mentioned in the Materials and Methods, calculations for the natural products in these trials are based on purchase prices of $\$ 8.00 / \mathrm{gal}$ for $30 \%$ acetic acid and $\$ 31.82 / \mathrm{gal}$ for technical grade $\mathrm{d}$-limonene.

The FWC National Pollution Discharge Elimination System (NPDES) report for 2018 lists diquat dibromide as one of four products that were used specifically for mosquitofern (Azolla sp.) management (Clark and Dew, 2019). Although the most commonly used product for feathered mosquitofern control was $51 \%$ water-dispersible granule flumioxazin (217.14 lb purchased), we used diquat dibromide for synthetic standard practice treatments to maintain consistency within the trials we report here and those conducted by Gettys et al. (2021). We did, however, use the amount of flumioxazin purchased to estimate the area of feathered mosquitofern treated. Recommended use rates for surface treatments with $51 \%$ water-dispersible granule flumioxazin are 6 to $12 \mathrm{oz} /$ acre formulated product $(0.19$ to $0.38 \mathrm{lb} /$ acre a.i.) (Valent USA Corp., 2012); therefore, $217.14 \mathrm{lb}$ would be used to treat 579.04 acres at $6 \mathrm{oz} /$ acre or 289.52 acres at $12 \mathrm{oz} /$ acre. The material cost to treat the same area with $0.22 \%$ diquat dibromide would be $\$ 10,277.96$ (579.04 acres) or $\$ 5138.98$ (289.52 acres).
Several natural treatments provided good control of feathered mosquitofern and acceptable selectivity of gulf coast spikerush. Acetic acid at $\geq 10 \%$, any rate of d-limonene, and any combination of the two reduced biomass and VC by $>90 \%$ compared with that of untreated controls of feathered mosquitofern. The material costs to make 1 gal of RTU 10\% acetic acid, $10 \%$ d-limonene, or $5 \%$ acetic acid plus $10 \% \mathrm{~d}$-limonene are $\$ 2.65$, $\$ 3.18$, and $\$ 4.51$, respectively. If these treatments are applied in a carrier volume equivalent to $100 \mathrm{gal} / \mathrm{acre}$ ( similar to diquat dibromide), then the product costs to treat 1 acre of feathered mosquitofern with $10 \%$ acetic acid or $10 \%$ d-limonene would be $\$ 265.00$ or $\$ 318.00$, respectively, whereas the product cost to treat 1 acre with $5 \%$ acetic acid plus $10 \%$ dlimonene would be $\$ 451.00$. If $10 \%$ acetic acid (the least expensive of these treatments) were used to treat feathered mosquitofern, then the material cost to treat 579.04 or 289.52 acres would be $\$ 153,445.60$ or $\$ 76,722.80$, respectively, representing a 15 -fold increase in the cost to treat the same areas with diquat dibromide.

The FWC's NPDES report for calendar year 2020 does not list products used specifically for managing common salvinia. However, the report indicates that $19.13 \mathrm{gal}$ of $37.3 \%$ diquat dibromide were used to manage the related giant salvinia (Salvinia molesta) in 2020 (Florida Fish and Wildlife Conservation Commission, 2021). If all treatments were mixed to a concentration of $0.22 \%$ diquat dibromide and applied in a carrier volume equivalent to $100 \mathrm{gal} /$ acre as indicated on the herbicide label (Syngenta Crop Protection, 2011), then a total of $3826 \mathrm{gal}$ of RTU mix were made from the 19.13 gal of concentrate purchased, with a calculated treatment area of 38.26 acres. The total material cost was \$679.12 (\$17.75/acre material cost). The only single-product "natural" treatments used during these trials that resulted in good control of common salvinia ( $>90 \%$ reduction in biomass) and acceptable selectivity of cattail $(<40 \%$ reduction in biomass) were $15 \%$ and $20 \%$ d-limonene. The material costs to make these concentrations of RTU d-limonene are $\$ 4.77 / \mathrm{gal}(15 \%)$ and $\$ 6.36 / \mathrm{gal}(20 \%)$. If $\mathrm{d}$-limonene is applied in a carrier volume equal to $100 \mathrm{gal} / \mathrm{acre}$ (as with diquat dibromide), then the material cost for treating a similar area (i.e., 38.26 acres) with $15 \%$ d-limonene would be $\$ 18$, 261.50 (\$477.30/acre), representing a 27 -fold increase from the $\$ 679.12$ (\$17.75/acre) spent to treat with $\mathrm{di}^{-}$ quat dibromide. Common salvinia and cattail had similar responses to mixes of acetic acid and d-limonene, and no treatment provided good control of common salvinia and good selectivity of cattail; therefore, cost comparisons of mixes to the synthetic standard diquat dibromide are not warranted.

Based on this information, it is clear that material costs would increase if synthetic herbicides such as diquat dibromide are replaced with "natural" products such as acetic acid and d-limonene. However, other costs are likely to increase as well. As reported by Gettys et al. (2021), applications using "natural" products would require more time because of the need to transport very large volumes of base material. For example, a typical spray boat is equipped with a 100-gal tank and uses carrier water drawn from the system being treated to dilute concentrated herbicide. Filling the tank once for a synthetic treatment would require the transport of $\approx 64 \mathrm{fl} \mathrm{oz}$ of $37.3 \%$ diquat dibromide; as such, a spray boat operator could set out with a single 2.5-gal jug of herbicide and have enough concentrate to make $500 \mathrm{gal}$ of RTU mix. In contrast, filling the tank once with the least expensive efficacious and selective "natural" treatment for feathered mosquitofern (10\% acetic acid) would necessitate transporting 33 gal of $30 \%$ acetic acid, or $\approx 330 \mathrm{lb}$ of material (without factoring in the weight of the containers used to transport the materials). Using 15\% d-limonene to treat common salvinia would require transporting $15 \mathrm{gal}(\approx 150 \mathrm{lb})$ of technical-grade d-limonene. Because of the added weight of the concentrated materials needed and limited space on the spray boat, applicators would likely "mix at the ramp" and, thus, would have to return to shore for reloading after applying $100 \mathrm{gal}$ of RTU natural mix.

\section{Conclusions}

The "natural" products evaluated in these studies may have some utility for selectively managing the small floating weeds feathered mosquitofern 
and common salvinia without causing unacceptable levels of damage to the desirable native plants gulf coast spikerush and cattail. Most single-product treatments provided good control of feathered mosquitofern with acceptable levels of damage to gulf coast spikerush, but only $15 \%$ and $20 \%$ dlimonene treatments were efficacious on common salvinia and selective for cattail. Some combinations of acetic acid and d-limonene provided acceptable control of both floating weeds and selectivity on gulf coast spikerush, but all mixes caused unacceptable levels of damage to cattail. Although the products examined in these studies act as contact herbicides and are not translocated, we observed that cattails struggled to recover after above-water foliar burn-back caused by treatment applications. Timmons et al. (1963) reported that cattail often fails to recover if aerial shoots are severed below the water line, a condition that could be mimicked by contact herbicide treatments such as those used in these studies. It is possible that plants in shallower (e.g., $<20 \mathrm{~cm}$ deep) water would be able to recover and regrow after treatments, but further investigations are needed to confirm this.

Replacing the currently used synthetic herbicides such as diquat dibromide with "natural" products such as acetic acid and d-limonene would result in significant increases in management costs. Treatment of feathered mosquitofern with $10 \%$ acetic acid instead of $0.22 \%$ diquat dibromide would increase material costs alone by 15 -fold, and switching from diquat dibromide to $15 \% \mathrm{~d}$-limonene for common salvinia control would result in a 27 -fold increase in product costs. As noted by Gettys et al. (2021), natural products such as acetic acid and d-limonene may be useful in some areas where synthetic herbicides are discouraged, but it is unlikely that broad-scale adoption of natural products for aquatic weed control would be an affordable option for most resource managers.

\section{Literature cited}

Bodle, M. 2008. Feathered mosquito fern (Azolla pinnata R. Br.) comes to Florida. Aquatics 30(2):4-8.
Clark, R. and A. Dew. 2019. Florida Fish and Wildlife Conservation Commission annual report of pollutant discharges to the surface waters of the state from the application of pesticides 1 Jan. 2018 through 31 Dec. 2018. 20 Mar. 2019. <https:// myfwc.com/media/19111/npdes-2018. pdf $>$.

Cutelle, M.A., G.R. Armel, J.T. Brosnan, D.A. Kopsell, W.E. Klingeman, P.C. Flanagan, G.K. Breeden, J.J. Vargas, R. Koepke-Hill, and M.A. Halcomb. 2013. Evaluation of container ornamental species tolerance to three $\mathrm{p}$-hydroxyphenylpyruvate dioxygenase-inhibiting herbicides. HortTechnology 23(3):319-324, https:// doi.org/10.21273/HORTTECH.23.3. 319.

Factory Direct Chemicals. 2019a. Concentrated vinegar. 20 Mar. 2019. <https://www.factorydirectchemicals.com/ collections/vinegars $>$.

Factory Direct Chemicals. 2019b. Citrus cleaners (d-limonene). 20 Mar. 2019. <https://www.factorydirectchemicals. com/collections/d-limonene $>$.

Florida Fish and Wildlife Conservation Commission. 2018. Florida Fish and Wildlife Conservation Commission Invasive Plant Management Section annual report of activities conducted under the Cooperative Aquatic Plant Control Program in Florida public waters for fiscal year 20172018. 10 June 2020. <https://myfwc. $\mathrm{com} / \mathrm{media} / 19112 /$ annualreport17-18. pdf $>$.

Florida Fish and Wildlife Conservation Commission. 2019. Florida Fish and Wildlife Conservation Commission Invasive Plant Management Section annual report of activities conducted under the Cooperative Aquatic Plant Control Program in Florida public waters for fiscal year 2018-2019. 10 June 2020. <https://myfwc.com/media/ 22606/annualreport1819_ipm.pdf $>$.

Florida Fish and Wildlife Conservation Commission. 2021. Annual report of pollutant discharges to the surface waters of the state from the application of pesticides 1 Jan. 2020 through 31 Dec. 2020. 10 May 2021. <https://myfwc.com/media/ 26168/npdes-2020.pdf $>$.

Gettys, L.A. 2019. Breaking bad: Native aquatic plants gone rogue and the invasive species that inspire them. HortTechnology 29(5):559-566, https://doi.org/ 10.21273/HORTTECH04333-19.

Gettys, L.A. and W.T. Haller. 2009. Tolerance of selected bedding plants to four herbicides in irrigation water. HortTechnology 19(3):546-552, https://doi.org/ 10.21273/HORTSCI.19.3.546.
Gettys, L.A. and W.T. Haller. 2010. Response of selected foliage plants to four herbicides in irrigation water. HortTechnology 20(5):921-928, https://doi. org/10.21273/HORTTECH.20.5.921.

Gettys, L.A. and W.T. Haller. 2012. Effect of herbicide-treated irrigation water on four vegetables. Weed Technol. 26(2):272278, https://doi.org/10.1614/WT-D11-00120.1.

Gettys, L.A. and K.A. Moore. 2018. Greenhouse culture and production of four ornamental native wetland plants. HortTechnology 28(3):332-336, https://doi. org/10.21273/HORTTECH03818-17.

Gettys, L.A. and K.A. Moore. 2019. Greenhouse production of native aquatic plants. HortTechnology 29(1):4l-45, https://doi.org/10.21273/HORTTECH 04212-18.

Gettys, L.A., K.L. Thayer, and J.W. Sigmon. 2021. Evaluating the effects of acetic acid and d-limonene on four aquatic plants. HortTechnology 31(2):225-233, https://doi. org/10.21273/HORTTECH04769-20.

Haller, W.T. and L.A. Gettys. 2013. Pond, selectivity and irrigation studies on potential new aquatic herbicides. Aquatics 35(2):6-10.

Jacono, C.C., T.R. Davern, and T.D. Center. 2001. The adventive status of Salvinia minima and $S$. molesta in the southern United States and the related distribution of the weevil Cyrtobagous salviniae. Castanea 66(3):214-226.

Koschnick, T.J., W.T. Haller, and G.E. MacDonald. 2005. Turf and ornamental plant tolerances to endothall in irrigation water: I Ornamental species. HortTechnology 15(2):318-323, https://doi. org/10.21273/HORTTECH.15.2.0318.

Madeira, P.T., T.D. Center, J.A. Coetzee, R.W. Pemberton, M.F. Purcell, and M.P. Hill. 2013. Identity and origins of introduced and native Azolla species in Florida. Aquat. Bot. 111:9-15, https://doi.org/ 10.1016/j.aquabot.2013.07.009.

Mudge, C.R., T.J. Koschnick, and W.T. Haller. 2007. Ornamental plant susceptibility to diquat in overhead irrigation water. J. Aquat. Plant Manage. 45:40-43.

Smith, H.C., J.A. Ferrell, and T.J. Koschnick. 2014. Flurprimidol performance on ornamental species in relation to trimming time and method of application. HortScience 49(10):1305-1308, https://doi. org/10.21273/HORTSCI.49.10.1305.

Stubbs, D. and C.R. Layne. 2020. Requirements for registration of aquatic herbicides, p. 155-162. In: L.A. Gettys, W.T. Haller, and D.G. Petty (eds.). Biology and control of aquatic plants: A best 
management practices handbook. 4th ed. Aquatic Ecosystem Restoration Foundation, Marietta, GA.

Syngenta Crop Protection. 2011. Tribune herbicide label. 3 Jan. 2021. <https:// www.greenbook.net/syngenta-llc/ tribune $>$.

Timmons, F.L., V.F. Bruns, W.O. Lee, R.R. Yeo, J.M. Hodgson, L.W. Weldon, and R.D. Comes. 1963. Studies on the control of common cattail in drainage canals and ditches. U.S. Dept. Agric. Tech. Bull.
1286. 29 Nov. 2021. <https://handle.nal. usda.gov/10113/CAT87201275>.

Tipping, P.W., M.R. Martin, L. Bauer, R.M. Pierce, and T.D. Center. 2012. Ecology of common salvinia, Salvinia minima Baker, in southern Florida. Aquat. Bot. 102:23-27, https://doi.org/ 10.1016/j.aquabot.2012.04.005.

Tootoonchi, M., L.A. Gettys, K.L. Thayer, I.J. Markovich, J.W. Sigmon, and S. Sadeghibaniani. 2020. Ecotypes of aquatic plant Vallisneria americana tolerate different salinity concentrations. Diversity (Basel) 12:65, https://doi.org/10.3390/ d12020065.

U.S. Environmental Protection Agency. 1996. Summary of the federal insecticide, fungicide, and rodenticide act. 4 Jan. 2021. <https://www.epa.gov/laws-regulations/ summary-federal-insecticide-fungicideand-rodenticide-act $>$.

Valent USA Corporation. 2012. Clipper herbicide label. 3 Mar. 2021. <http:// www.cdms.net/LDat/ld9PS003.pdf $>$. 